\title{
Polinização de Vochysia lucida C. Presl (Vochysiaceae) em uma área de restinga na Bahia
}

\begin{abstract}
Miriam Gimenes ${ }^{1}$
${ }^{1}$ Depto. de Ciências Biológicas, Universidade Estadual de Feira de Santana, Km 03, BR 116, 44031-460, Feira de Santana-BA. mgimenes@uefs.br

ABSTRACT. Pollination of Vochysia lucida C. Presl (Vochysiaceae) in an area of restinga in Bahia State. Vochysia species are Neotropical and present flowers that can be visited by bees, hummingbirds, and butterflies. This study aimed to analyze the interactions between the flowers of Vochysia lucida and their floral visitors in an area of restinga in Bahia State, Brazil. V. lucida is an arborescent species and presents inflorescences of the type raceme, with about 100 to 170 flowers. The flowers are zygomorphic, yellow-coloured, and considered mellitophilous. The floral nectar is produced and stored in the spur, which is localized at the calyx. The flowering peak of $V$. lucida was in November and December. All through the study the flowers opened at $6 \mathrm{~h}$., when the stigma was already receptive. At flower opening the anther was already not more present and the pollen grains were deposited in the wall of the style, occurring secondary presentation of pollen. Petals dropped in the end of the afternoon about 17:00 h. The hummingbirds, although frequent in the flowers of $V$. lucida, were considered as opportunistic visitors. Among the recorded floral visitors, the large bees were regarded the most efficient pollinators, especially Xylocopa frontalis, because it has suitable morphology and behavior to contact the reproductive structures of the flower, during nectar collections, and for its high visiting frequency.
\end{abstract}

KEYWORDS. Apoidea; Apidae; Bee-flower interaction; Trochilidae.

RESUMO. Polinização de Vochysia lucida C. Presl (Vochysiaceae) em uma área de restinga na Bahia. As espécies de Vochysia são neotropicais e apresentam flores que podem ser visitadas por abelhas, beija-flores e borboletas. Este estudo teve como objetivo a análise das interações entre as flores de Vochysia lucida e seus visitantes florais, em uma área de restinga no Estado da Bahia, Brasil. V. lucida é uma espécie arbórea e apresenta inflorescências do tipo racemo, com cerca de 100 a 170 flores. As flores são zigomorfas, amarelas e foram consideradas melitófilas. O néctar floral é produzido e estocado em esporão, localizado no cálice. O pico de floração de V. lucida ocorreu em novembro e dezembro. Durante o estudo as flores abriam às 6:00 h, quando o estigma já estava receptivo. Na abertura da flor a antera já não estava mais presente e os grãos de pólen estavam depositados na parede do estilete, ocorrendo apresentação secundária de pólen. As pétalas caíam no final da tarde, por volta das 17:00 h. Os beija-flores embora freqüentes nas flores de $V$. lucida foram considerados visitantes oportunistas. Entre os visitantes florais registrados, as abelhas de grande porte foram consideradas os polinizadores mais eficientes, especialmente Xylocopa frontalis, por ter morfologia e comportamento adequados para contatar as estruturas reprodutivas da flor, durante as coletas de néctar, e por sua elevada freqüência de visita.

PALAVRAS-CHAVE. Apoidea; Apidae; Interação abelha-flor; Trochilidae.

A restinga pode ser definida como "vegetação com influência marinha", que cobre cerca de 79\% do litoral brasileiro, e localiza-se entre ambientes marinho e continental. Estes ecossistemas costeiros, característicos da zona meridional e norte do Brasil, são cobertos principalmente por vegetação herbácea arbustiva e apresentam solos arenosos, ácidos e pobres em nutrientes. Estas condições propiciam o desenvolvimento de uma flora e fauna com características próprias, reflexo dos fatores físicos dominantes: salinidade, extremos de temperatura, ventos fortes e carregados de sal vindos do oceano, escassez de água, insolações fortes e diretas sendo atualmente considerado ecossistema de grande fragilidade no contexto do macrozoneamento do litoral brasileiro (MMA 1996 apud Lacerda \& Esteves 2000).

Segundo Gottsberger et al. (1988), em dunas e restingas costeiras há o predomínio da melitofilia porém as informações a respeito das interações entre as flores e seus polinizadores na restinga são escassas, destacando-se os estudos das relações entre as abelhas e as flores nestes ecossistemas no
Maranhão (Gottsberger et al. 1988), na Paraíba (Silva \& Martins 1999), na Bahia (Costa \& Ramalho 2001; Ramalho \& Silva 2002; Oliveira-Rebouças \& Gimenes 2004; Viana \& Kleinert 2005), em Pernambuco (Teixeira \& Machado 2000), no Rio de Janeiro (Pinheiro et al. 1988) e no Rio Grande do Sul (Alves-dos-Santos 1999).

Dentre as espécies de plantas que são geralmente encontradas em dunas e restingas no Brasil, algumas do gênero Vochysia (Vochysiaceae) são comuns. A família Vochysiaceae possui seis gêneros com distribuição neotropical (Cronquist 1981), sendo que o gênero Vochysia engloba 100 espécies bem distribuídas nas diversas regiões do Brasil, especialmente nos ecossistemas de Cerrado do Brasil central (Barroso, 1984) e 19 que ocorrem no Estado da Bahia (Stafleu 1948). Segundo Flavio França (informação pessoal) apenas Vochysia lucida e $V$. riedeliana, ocorrem em áreas de restinga na Bahia.

Uma das características mais interessantes das flores dos gêneros Vochysia e Salvertia (Vochysiaceae) é a apresentação secundária de pólen. Nestas plantas, os grãos de pólen são 
transferidos das anteras para o estilete, antes mesmo das flores estarem totalmente abertas, funcionando o estilete como a estrutura onde o pólen fica depositado, sendo o estigma terminal. Dessa forma, quando as flores começam a abrir e a receber os primeiros visitantes florais, a maioria já perdeu as anteras (Oliveira \& Gibbs 1994; Oliveira, 1996; Santos et al. 1997; Oliveira 1998).

Poucas espécies de Vochysia têm sido estudadas com relação à biologia da polinização. Visitantes florais e polinizadores compreendem principalmente abelhas da família Apidae. Oliveira \& Gibbs (1994) estudaram a biologia floral de seis espécies de Vochysia que ocorrem no cerrado do Brasil e Santos et al. (1997), V. cinnamonea Pohl nos cerrados do Triângulo Mineiro. Esses autores verificaram que as abelhas de grande porte pertencentes à família Apidae, especialmente do gênero Epicharis, foram os principais polinizadores das flores.

Outros visitantes florais como beija-flores e mariposas também foram observados em várias espécies de Vochysia (Oliveira 1996; Oliveira et al. 2004). Em vários destes estudos o comportamento destes animais foi considerado oportunista, pois estes coletavam o néctar à distância, de modo que raramente contatavam o pólen ou a superfície estigmática (Oliveira \& Gibbs 1994; Santos et al. 1997).

Algumas informações indicam que uma pequena diferença no tamanho da flor ou no habitat entre as várias espécies de Vochysia pode influenciar a importância relativa das abelhas versus beija-flores ou esfingídeos como seus polinizadores efetivos nas diferentes espécies (Oliveira 1998).

Este estudo foi realizado em uma área restrita em ambiente de restinga no Litoral Norte da Bahia, com o objetivo de investigar as interações entre Vochysia lucida e seus visitantes florais, com enfoque nos aspectos morfológicos, comportamentais e temporais de ambos os organismos.

\section{MATERIALE MÉTODOS}

O trabalho foi desenvolvido, de janeiro/2001 a janeiro/2002, em uma área de restinga, no Sítio Mingú em Arembepe (1243’42" S e 38 08'49" W) (Município de Camaçari), Litoral Norte, Bahia, Brasil, pertencente à Área de Proteção Ambiental do Rio Capivara (criada pelo decreto ${ }^{\circ} 2.219$ de 14/06/93). O clima de Camaçari é tropical quente e úmido (AM, classificação de Köppen). A pluviosidade total durante o ano de 2001 foi de $1528 \mathrm{~mm}$ e a estação chuvosa ocorreu entre março e outubro. A temperatura média anual variou de 23 a $27^{\circ} \mathrm{C}$ (Fig. 1). Os dados climáticos diários de temperatura, umidade relativa e intensidade luminosa, próximos da área de estudo foram registrados em intervalos de uma hora durante todo o tempo de observação.

A área do sítio Mingú tem aproximadamente 5 ha, com a vegetação muito preservada. Esta caracteriza-se por uma cobertura vegetal herbáceo-arbustiva, composta principalmente por espécies de Melastomataceae, Scrophulariaceae, Krameriaceae, Leguminosae e Lythraceae, e por um estrato arbóreo-arbustivo dominado por espécies de
Malpighiaceae e principalmente por V. lucida (Vochysiaceae). Segundo a classificação proposta por Araújo et al. 1998 (apud Cogliatti-Carvalho et al. 2001), na região estudada foram reconhecidas as formações arbustivas abertas de Clusia e de Ericaceae e mata periodicamente inundada.

Para caracterização das flores de V. lucida na restinga de Arembepe, foram realizadas descrições da forma e cor das mesmas. Também foram feitas medidas do comprimento das inflorescências, flores, pétalas e esporão com paquímetro.

Dez indivíduos de V. lucida foram acompanhados mensalmente, para estudos do florescimento, nos quais foram considerados os dados sobre a presença de inflorescências com flores abertas, sendo a contagem realizada no indivíduo de V. lucida mais florido.

Foram feitas observações das atividades dos visitantes florais, em um indivíduo de $V$. lucida, das 4:30 às 18:00 h, em três dias consecutivos, nos meses de outubro e dezembro e um dia no mês de novembro de 2001, totalizando 7 dias (92 horas e $30 \mathrm{~min}$ ) de amostragem. Foram realizadas observações sobre o horário em que estes visitantes coletavam néctar nas flores e o comportamento de coleta de recursos florais. A frequiência de coleta de recurso pelos visitantes foi obtida através da contagem do número de visitas nas flores de cerca de 40 inflorescências de um indivíduo, nos meses de outubro e dezembro/2001, totalizando seis dias de amostragem. Estes dados foram plotados na forma de categorias e quando as abelhas realizavam um total de uma a cinco visitas em três dias eram consideradas pouco freqüentes, de seis a 20 visitas, com frequiência média baixa, de 21 a 50 visitas, freqüência média alta e acima de 51 visitas muito freqüente, para cada mês observado.

A receptividade do estigma foi detectada através da reação da superfície do estigma com água oxigenada 10 volumes (Dafni 1992).

Para verificar a presença de osmóforos, foi administrada solução aquosa de vermelho neutro (1:1000), nas diversas partes da flor. As flores foram imersas nesta solução e após 10 minutos, eram lavadas com água destilada e verificada a formação de manchas que podem indicar a localização dos osmóforos. Foi realizado o ensaio de concentração de odor com cem flores em saco plástico mantido fechado por uma hora, sendo então verificada a presença de odor.

Foram feitas medidas do comprimento (do ocelo médio ao ápice do abdomen) e da largura (entre as tégulas) do corpo de 10 indivíduos de cada espécie de abelha visitante (com exceção de Epicharis bicolor, onde as medidas foram realizadas apenas em um indivíduo). Para classificar o tamanho das abelhas foram utilizadas as categorias de Viana \& Kleinert (2005) (adaptado segundo a classificação de Roubik 1989 e Michener 2000).

Foram confeccionadas lâminas com o pólen presente nas cerdas da parte ventral do protórax e da escopa de Xylocopa frontalis (por ser este o visitante mais comum nas flores de $V$. lucida na área de estudo) e também das anteras de V. lucida, para comparação.

As abelhas foram identificadas pelo Prof. Dr. Fernando C. Zanella (UFPB) e Prof. Edinaldo L. das Neves (UFBA) e 
depositadas no MZUEFS (Museu de Zoologia da Universidade Estadual de Feira de Santana). Material testemunho dos espécimes de Vochysia coletados foram identificados pelo Prof. Dr. Flavio França e estão depositados no HUEFS (Herbário da UEFS). Os beija-flores foram identificados pelo Prof. Dr. Caio Gracco Machado e Miguel Ângelo da Silva Colaço através das descrições feitas em campo quando estavam em atividade nas flores.

\section{RESULTADOS}

Espécimes de V. lucida ocorrem em toda a área do Sítio Mingú. O maior número de inflorescências com flores abertas e botões foi observado de outubro a dezembro, com o pico de floração em novembro e dezembro (com mais de 100 inflorescências por planta) (Fig. 1), correspondentes a meses com baixos valores de precipitação (estação seca). Nesta fase, a maior parte das inflorescências apresentava cerca de $100 \mathrm{a}$ 170 flores e botões. De janeiro a setembro, o número de inflorescências foi reduzido, sendo observadas menos de cinco por planta e em outubro a maior parte dos indivíduos apresentou de 10 a 50 inflorescências (Fig. 1).

Os indivíduos de V. lucida apresentavam porte arbóreo com cerca de 2 a 4 metros de altura, sendo que alguns podiam atingir até 10 metros. As inflorescências de V. lucida são racemos com cerca de $30 \mathrm{~cm}$ de comprimento do tipo terminal em forma de "pirâmide". As flores são hermafroditas, zigomorfas, com 23 a $26 \mathrm{~mm}$ de comprimento, incluindo o esporão (onde o néctar é produzido). Apresentavam cor amarelo-viva, cálice gamossépalo pentâmero com um grande esporão e três pétalas, um único e grande estame em frente à pétala central, uma única antera e um único estigma. As pétalas apresentavam de 7 a 9 mm de comprimento e o esporão ca. de $10 \mathrm{~mm}$.

Foi detectada, através da aplicação de vermelho neutro, a presença de osmóforos nas pétalas, na forma de pequenas

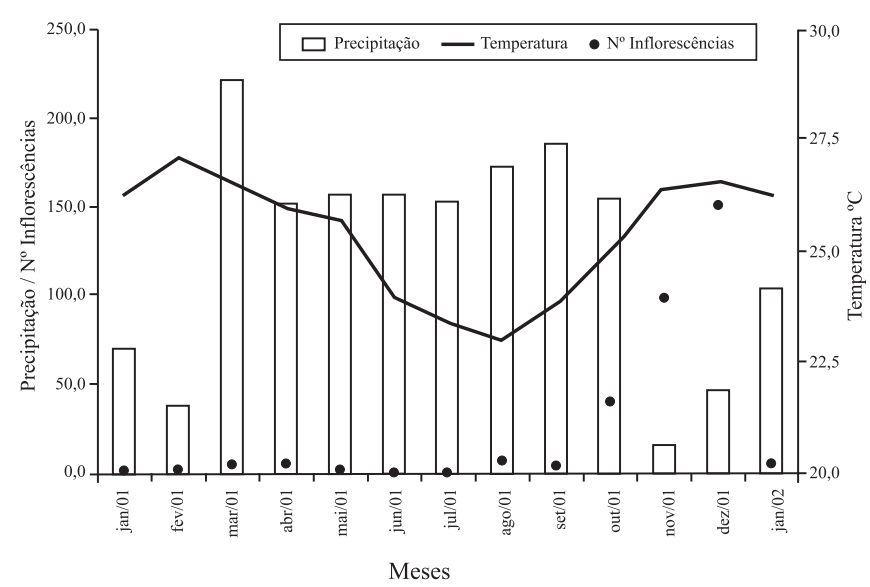

Fig. 1. Dados climáticos referentes à temperatura média e precipitação pluviométrica (dados macroclimáticos obtidos junto à CETREL S.A., Empresa de Proteção Ambiental) e número total de inflorescências de Vochysia lucida em Arembepe, BA, nos meses de janeiro de 2001 a janeiro de 2002 .
Tabela I. Largura do tórax e comprimento ( $\mathrm{mm})$ das fêmeas das abelhas visitantes de Vochysia lucida em vegetação de restinga em Arembepe, BA. DP = Desvio padrão.

\begin{tabular}{|c|c|c|}
\hline Espécies & Largura & Comprimento \\
\hline $\begin{array}{l}\text { Xylocopa frontalis } \\
\text { (Olivier, 1789) }\end{array}$ & $8,84(\mathrm{DP}=0,57)$ & $30,12(\mathrm{DP}=1,73)$ \\
\hline Centris sponsa & & \\
\hline $\begin{array}{l}\text { Smith, } 1854 \\
\text { Eulaema nigrita }\end{array}$ & $8,30(\mathrm{DP}=1,03)$ & $22,70(\mathrm{DP}=0,45)$ \\
\hline $\begin{array}{l}\text { Lepeletier, } 1841 \\
\text { Centris leprieuri }\end{array}$ & $7,20(\mathrm{DP}=0,27)$ & $18,17(\mathrm{DP}=0,65)$ \\
\hline $\begin{array}{l}\text { (Spinola, 1841) } \\
\text { Xylocopa cearensis }\end{array}$ & $6,40(\mathrm{DP}=0,46)$ & $16,40(\mathrm{DP}=1,00)$ \\
\hline $\begin{array}{l}\text { Ducke, } 1910 \\
\text { Xylocopa subcyanea }\end{array}$ & $5,85(\mathrm{DP}=0,33)$ & $18,45(\mathrm{DP}=1,63)$ \\
\hline $\begin{array}{l}\text { Pérez, } 1901 \\
\text { Epicharis bicolor }\end{array}$ & $4,86(\mathrm{DP}=0,18)$ & $14,65(\mathrm{DP}=0,89)$ \\
\hline Smith, 1874 & 4,48 & 13,76 \\
\hline $\begin{array}{l}\text { Euglossa sp. } \\
\text { Centris tarsata }\end{array}$ & $4,60(\mathrm{DP}=0,24)$ & $9,67(\mathrm{DP}=0,70)$ \\
\hline $\begin{array}{l}\text { Smith, } 1874 \\
\text { Apis mellifera }\end{array}$ & $4,24(\mathrm{DP}=0,18)$ & $11,40(\mathrm{DP}=0,76)$ \\
\hline Linnaeus, 1758 & $3,55(\mathrm{DP}=0,04)$ & $10,16(\mathrm{DP}=0,37)$ \\
\hline
\end{tabular}

manchas arredondadas e agrupadas no seu ápice. O odor foi identificado como adocicado, semelhante a mel.

Durante os meses de outubro a dezembro, as flores de $V$. lucida estavam completamente abertas (com as pétalas distendidas) por volta das 6:00 h. Durante este tempo a temperatura variou de 23 a $28^{\circ} \mathrm{C}$, a umidade relativa de 77 a $96 \%$ e a intensidade luminosa de 2200 a 24000 lux. As pétalas caíam no final da tarde, aproximadamente às 17:00 h, permanecendo na inflorescência o cálice com o esporão e o gineceu.

Quando a flor abria a única antera podia já ter caído ou estar bem próxima ao estilete, caindo logo em seguida, ficando o pólen depositado na parede lateral do estilete, caracterizando-se como uma deposição secundária de pólen. Neste caso, o pólen não ficava disponível aos visitantes florais na antera, mas sim na parede do estilete. Como o estigma era terminal, aparentemente não havia o contato do pólen presente na parede do estilete com o estigma. Na abertura das flores, o estigma já se encontrava receptivo.

As flores de $V$. lucida foram preferencialmente visitadas por abelhas (Apoidea) de diferentes tamanhos (Tabela I). Xylocopa frontalis, Centris sponsa, Eulaema nigrita, Centris leprieuri e Xylocopa cearensis foram consideradas de grande porte (mais de $14 \mathrm{~mm}$ de comprimento), Xylocopa subcyanea e Epicharis bicolor abelhas de tamanho médio robusta e Euglossa sp. Centris tarsata e Apis mellifera abelhas médias.

$X$. frontalis, bem como as outras abelhas de grande porte (Tabela I), pousavam frontalmente nas flores e coletavam néctar do esporão. Estas abelhas tocavam o estilete e também o estigma com a parte ventral da cabeça e do protórax. Análises palinológicas indicaram grãos de pólen de $V$. lucida nestas 
Tabela II. Número total de visitas das abelhas e beija-flores nas flores de um indivíduo de Vochysia lucida durante três dias de observação no mês de outubro/2001. $\mathrm{X}=$ de 1 a 5 visitas; $\mathrm{XX}=6$ a 20; $\mathrm{XXX}=$ de 21 a 50 visitas, $\mathrm{XXXX}=$ acima de 51 visitas .

\begin{tabular}{lccccc}
\hline Horário & $\begin{array}{c}\text { X. } \\
\text { frontalis }\end{array}$ & $\begin{array}{c}\text { E. } \\
\text { nigrita }\end{array}$ & Euglossa & Amazilia & E.macroura \\
\hline 5:00 & $\mathrm{X}$ & & & & \\
$6: 00$ & & & $\mathrm{X}$ & $\mathrm{X}$ & $\mathrm{X}$ \\
7:00 & $\mathrm{X}$ & $\mathrm{X}$ & $\mathrm{X}$ & $\mathrm{X}$ & \\
$8: 00$ & $\mathrm{X}$ & $\mathrm{X}$ & $\mathrm{X}$ & $\mathrm{X}$ & $\mathrm{X}$ \\
9:00 & $\mathrm{XXXX}$ & & $\mathrm{XX}$ & $\mathrm{X}$ & $\mathrm{XXX}$ \\
$10: 00$ & $\mathrm{X}$ & & $\mathrm{X}$ & $\mathrm{X}$ & $\mathrm{XXXX}$ \\
$11: 00$ & $\mathrm{X}$ & & & $\mathrm{X}$ & $\mathrm{XXXX}$ \\
$12: 00$ & $\mathrm{XXXX}$ & & $\mathrm{X}$ & $\mathrm{XXXX}$ & $\mathrm{X}$ \\
$13: 00$ & $\mathrm{X}$ & & & $\mathrm{X}$ & $\mathrm{XXX}$ \\
$14: 00$ & $\mathrm{XX}$ & & $\mathrm{X}$ & $\mathrm{XXXX}$ & $\mathrm{X}$ \\
$15: 00$ & $\mathrm{XXX}$ & & & $\mathrm{XXX}$ & $\mathrm{XX}$ \\
$16: 00$ & & & $\mathrm{XX}$ & \\
$17: 00$ & & & & $\mathrm{XX}$ & \\
\hline
\end{tabular}

estruturas. Essas abelhas algumas vezes pairavam no ar, retirando com suas pernas anteriores, o pólen que estava depositado na parte ventral do seu corpo. Este pólen provavelmente estava sendo transferido para a escopa. Análises palinológicas evidenciaram a presença de pólen de $V$. lucida na escopa de $X$. frontalis.

As abelhas de tamanho médio e médio robusto como Euglossa sp. e X. subcyanea (Tabela I), nas coletas de néctar em V. lucida, raramente tocavam o estilete e o estigma, devido ao seu pequeno porte,e por permanecerem distantes do estigma quando coletavam com suas línguas longas.

As flores de $V$. lucida também foram visitadas por beijaflores Amazilia sp. e Eupetomena macroura (Gmelin, 1788) (Trochilidae) e, esporadicamente, por borboletas. Nas coletas de néctar esses visitantes inseriam as longas línguas no esporão da flor ficando o restante do corpo longe das estruturas reprodutivas, tocando-as raramente.
De modo geral, os visitantes florais chegavam por volta das 5:00 h (antes das flores estarem completamente abertas) e permaneciam coletando néctar até às 17:00 h. Em outubro, início da fase reprodutiva de $V$. lucida, as flores foram visitadas tanto por abelhas (principalmente $X$. frontalis) como por beijaflores (Tabela II). Porém, no mês de dezembro (pico de floração) houve predominância de abelhas visitando as flores (Tabela III).

Fêmeas de $X$. frontalis foram os visitantes mais freqüentes nas flores de $V$. lucida, especialmente durante os meses de maior florescimento. Elas coletavam néctar das 5:30 às 15:00 h, principalmente das 6:00 às 9:00 h (Tabela III), coincidente com o horário de receptividade do estigma e com a liberação do pólen. Durante este horário a temperatura variou de 26 a $32{ }^{\circ} \mathrm{C}$ e a umidade relativa de 74 a $88 \%$.

As visitas dos beija-flores Amazilia sp. e E. macroura nas flores de $V$. lucida ocorreram principalmente no mês de outubro, início da fase reprodutiva desta planta. Estas visitas ocorriam especialmente das 10:00 às 11:00 h para E. macroura e das 12:00 às 14:00 h para Amazilia sp. (Tabela II). Durante o pico de floração, em dezembro, as visitas destes beija-flores ocorreram apenas esporadicamente, nos três dias de observação (Tabela III).

No mês de outubro $X$. frontalis, Amazilia sp. e E. macroura visitavam as flores de $V$. lucida das 5:00 às 15:00 h, sendo observadas interações agonísticas entre eles, principalmente entre as abelhas e os beija-flores. No mês de dezembro, estas agressões ocorreram mais entre $X$. frontalis e $C$ sponsa, pois os beija-flores foram observados mais raramente nas flores (Tabela III).

Nos meses de janeiro a setembro foram observadas visitas de abelhas especialmente A. mellifera e Euglossa sp. e beijaflores, nas poucas flores de V. lucida presentes.

\section{DISCUSSÃO}

O florescimento de $V$. lucida na restinga estudada ocorreu principalmente em novembro e dezembro, como também foi

Tabela III. Número total de visitas das abelhas e beija-flores nas flores de um indivíduo de Vochysia lucida durante três dias de observação no mês de dezembro/2001. $\mathrm{X}=$ de 1 a 5 visitas; $\mathrm{XX}=6$ a 20; $\mathrm{XXX}=$ de 21 a 50 visitas, $\mathrm{XXXX}=$ acima de 51 visitas.

\begin{tabular}{|c|c|c|c|c|c|c|c|c|}
\hline Horário & $X$. front. & C. sponsa & C. lepr. & X. subc. & Euglossa & A. mellif. & Amazilia & Eupetom. \\
\hline 5:00 & XXX & & & & & XXX & & $\mathrm{X}$ \\
\hline $6: 00$ & XXXX & $X$ & $X$ & & & XXX & XX & \\
\hline $7: 00$ & XXXX & XX & & & & & & \\
\hline $8: 00$ & XXXX & $X$ & $X$ & $X$ & & $X$ & & \\
\hline 9:00 & XXXX & & & & $X$ & $X$ & & \\
\hline 10:00 & X & XX & X & $X$ & & & & \\
\hline 11:00 & XXXX & $\mathrm{X}$ & XXX & & & XXX & & $\mathrm{X}$ \\
\hline \multicolumn{9}{|l|}{$12: 00$} \\
\hline $13: 00$ & XXXX & XX & & & & XXX & & \\
\hline $14: 00$ & X & XXX & & & & & & \\
\hline $15: 00$ & XXX & & & & & XXX & & \\
\hline $16: 00$ & & XXX & & & $X$ & X & & XX \\
\hline $17: 00$ & & & & $X$ & & $X$ & XX & \\
\hline
\end{tabular}


observado para V. tucanorum (Spr.) Mart no cerrado de Brasília (Oliveira \& Gibbs 1994). Oliveira \& Gibbs (1994) trabalhando com cinco outras espécies de Vochysia no cerrado do Brasil central, verificaram diferentes meses de florescimento. Santos et al. (1997) observaram para Vochysia cinnamomea Pohl. floração em março e abril, no cerrado de Minas Gerais.

As flores de V. lucida na restinga estudada abriam de manhã cedo, logo após o nascer do sol. Oliveira \& Gibbs (1994) e Santos et al. (1997) observaram que em outras espécies de Vochysia em áreas de cerrado do Brasil as flores abriam por volta das 10:00 h.

As flores de V. lucida foram visitadas preferencialmente por abelhas e consideradas melitófilas segundo o conceito de Faegri \& Van der Pijl (1979) por serem zigomorfas, de cor amarela, apresentarem plataforma de pouso, odor fraco, néctar escondido e poucos estames. As abelhas de grande porte, especialmente $X$. frontalis, foram consideradas os polinizadores mais eficientes das flores de V. lucida devido ao comportamento de coleta de néctar, pelo tamanho do corpo adequado e à elevada frequiência de visitas. Além disso, houve sincronização entre o horário de abertura das flores, receptividade do estigma, apresentação do pólen e a fase de maior atividade de $X$. frontalis, ao longo do dia, durante o mês de dezembro (pico de floração). As abelhas de médio porte foram consideradas polinizadores casuais de V. lucida, pois entravam eventualmente em contato com as estruturas reprodutivas das flores.

Segundo Gottsberger et al. (1988) existiria uma dominância de espécies de plantas melitófilas polinizadas, especialmente, por abelhas de grande porte, principalmente dos gêneros Xylocopa e Centris, em áreas de restinga. A coleta de recursos florais em ambientes arenosos de dunas e restingas por abelhas de pequeno porte fica dificultada especialmente pela ocorrência de ventos fortes nestes ambientes.

A associação de flores de Vochysia com abelhas de grande porte especialmente da tribo Centridini também foi observada por vários autores em ambiente de cerrado (Oliveira \& Gibbs 1994; Santos et al. 1997; Oliveira 1998). Santos et al. (1997) estudando V. cinnamomea no cerrado de Uberlândia (MG) observaram que as abelhas do gênero Epicharis foram os visitantes principais e mais comuns nas flores. Porém, a composição de espécies de abelhas visitantes de Vochysia spp. nestes estudos foi diferente da observada para $V$. lucida na restinga de Arembepe, especialmente com relação à $X$. frontalis não citada como visitante floral nos estudos do cerrado. Todas as abelhas observadas visitando as flores de $V$. lucida na restinga também foram observadas em áreas de dunas costeiras em Salvador (BA), sendo algumas espécies bastante freqüentes neste ambiente, como $C$. leprieuri, $X$. cearensis e A. mellifera (Viana \& Kleinert 2005).

Embora as flores de V. lucida tenham sido consideradas melitófilas, também foram visitadas por beija-flores e, menos freqüentemente, por borboletas. Estes visitantes não foram considerados polinizadores eficientes, podendo ser considerados pilhadores ou visitantes oportunistas, pois contatavam o estigma das flores apenas eventualmente, em comparação com as abelhas. Além disso, durante o pico de florescimento de $V$. lucida os beija-flores chegavam mais tarde nas flores, provavelmente quando estas já haviam sido polinizadas pelas abelhas. Oliveira \& Gibbs (1994) e Santos et al. (1997) também verificaram a presença de beija-flores e borboletas visitando as flores de Vochysia spp. em áreas de cerrado, porém estes foram considerados polinizadores secundários, casuais ou oportunistas, pela pequena quantidade de pólen que podiam transferir em cada visita às flores.

Segundo Oliveira (1998) a importância relativa entre abelhas e beija-flores na polinização de Vochysia depende das diferenças no tamanho das flores e do habitat das plantas. As flores de Vochysia spp. relativamente grandes que ocorrem no campo rupestre, ecossistema em altitudes elevadas, poderiam ser mais dependentes dos beija-flores para sua polinização do que das abelhas (Oliveira 1998). Já em ecossistema de cerrado e restinga, ambientes de vegetação relativamente aberta e em baixas altitudes, existiria a predominância da polinização das flores de Vochysia por abelhas de grande porte, como foi observado no cerrado e no presente estudo, na restinga.

Agradecimentos. Agradecemos aos proprietários do Sítio Mingu por terem permitido o desenvolvimento do trabalho de campo, e à UEFS pelo auxílio financeiro na execução do projeto. A Fernando C. V. Zanella (UFCG) e Edinaldo L. das Neves (UFBA) pela identificação das abelhas, Caio Gracco Machado e Miguel Ângelo da Silva Colaço pela identificação dos beija-flores e Flavio França pela identificação da espécie vegetal. A Luciano Paganutti Queiroz pela leitura crítica do texto. A Eraldo Medeiros Costa Neto pela revisão do abstract. A Marcos da Costa Dórea pelo auxílio nas análises palinológicas.

\section{REFERÊNCIAS}

Alves-dos-Santos, I. 1999. Abelhas e plantas melíferas da mata atlântica, restinga e dunas do litoral norte do estado do Rio Grande do Sul. Revista Brasileira de Entomologia 43: 191-223.

Barroso, G. M. 1984. Sistemática de Angiospermas do Brasil. Imprensa da Universidade Federal de Viçosa, Viçosa. 326 p.

Costa, J. A. S. \& M. Ramalho. 2001. Ecologia da polinização em ambientes de Duna Tropical (APA do Abaeté, Salvador, Bahia, Brasil). Sitientibus série Ciências Biológicas 1: 135-145.

Cogliatti-Carvalho, L.; A. F. N. Freitas; F. D. Rocha \& M. Van Sluys 2001. Variação na estrutura e na composição de Bromeliaceae em cinco zonas de restingas no Parque Nacional da Restinga de Jurubatiba, Macaé, RJ. Revista Brasileira de Botânica 24: 112.

Cronquist, A. 1981. An integrated system of classification of flowering plants. Columbia University Press, New York. 1262 p.

Dafni, A. 1992. Pollination Ecology. A practical approach. IRL Press at Oxford University Press, Oxford, New York, Tokyo. 250p.

Faegri, K \& L. Van der Pijl. 1979. The principles of pollination ecology, 3a. ed., Pergamon Press, London. 244 p.

Gottsberger, G., J. M. F. Camargo \& I. Silberbauer-Gottsberger. 1988. A bee-pollinated tropical community: The beach dune vegetation of Ilha de São Luís, Maranhão, Brazil. Botanische Jahrbücher für Systematik 109: 469-500.

Lacerda, L. D. \& F. A. Esteves 2000. Restingas Brasileiras: Quinze Anos de Estudo. Texto de Apresentação. In: Esteves, F. A. \& L. D. Lacerda. (eds.). Ecologia das Restingas e das Lagoas Costeiras. Rio de Janeiro. Ed. Nupem/UFRJ. 394 p. 
Michener, C. D. 2000. The Bees of the World. Baltimore, Johns Hopkins University Press, xiv+913 p.

Oliveira, P. E. 1996. Biologia floral de Salvertia convallariodora (Vochysiaceae): uma espécie de cerrado polinizada por mariposas. Revista Brasileira de Botânica 19: 49-53.

Oliveira, P. E. 1998. Reproductive biology, evolution and taxonomy of Vochysiaceae in Central Brazil, p. 381-393. In: S. J. Owens \& P. J. Rudall. (eds). Reproductive Biology in Systematics, Conservation and Economic Botany. Royal Botanic Gardens, Kew, 513 p.

Oliveira, P. E. \& P. Gibbs. 1994. Pollination biology and breeding systems of six Vochysia species (Vochysiaceae) in Central Brazil. Journal of Tropical Ecology 10: 509-522.

Oliveira, P.; P. E. Gibbs \& A. A. Barbosa. 2004. Moth pollination of woody species in the cerrados of Central Brazil: a case of so much owed to so few? Plant Systematics And Evolution 245: 41-54.

Oliveira-Reboucas, P. \& M. Gimenes. 2004. Bee (Apoidea) visitors of the flowers of Comolia ovalifolia DC Triana (Melastomataceae) in a sandbanks area in Bahia. Neotropical Entomology 33: 315320.

Pinheiro, M. C. B.; W. T. Ormond; C. O. Leite \& H. A. Lima. 1988. Ecologia da polinização de Chamaecrista ramosa (Vog.) Irnn e Barn var. ramosa. Ver. Revista Brasileira de Biologia 48: 665672
Ramalho, M. \& M. Silva 2002. Flora Oleífera e sua Guilda de Abelhas em uma Comunidade de Restinga Tropical. Sitientibus Série Ciências Biológicas 2: 34-43.

Roubik, D. W. 1989. Ecology and natural history of tropical bees. Cambridge, University Press, $514 \mathrm{p}$.

Santos, M. L.; A. de P. Afonso \& P. E. Oliveira. 1997. Biologia floral de Vochysia cinnamomea Pohl (Vochysiaceae) em cerrados do Triângulo Mineiro, MG. Revista Brasileira de Botânica 20 127-132.

Silva, M. C. M. \& C. Martins. 1999. Flora apícola e relações tróficas de abelhas (Hymenoptera: Apoidea) em uma área de duna (praia de Interlagos, Cabedelo-PB, Brasil). Principia (CEFET-PB) 7: 40 50 .

Stafleu, F. A. 1948. A monograph of the Vochysiaceae. I. Salvertia and Vochysia. Recueil des Travaux Botanique Néerlandaise 41: $397-$ 540.

Teixeira, L. A. G. \& I. C. Machado. 2000. Sistema de polinização e reprodução de Byrsonima sericea DC (Malpighiaceae). Acta Botanica Brasilica 14: $347-357$.

Viana, B. F. \& A. M. P. Kleinert 2005. A community of flower-visiting bees (Hymenoptera: Apoidea) in the coastal sand dunes of Norheastern Brazil. Biota Neotropica 5: 1-13. 